\title{
LA IMPORTANCIA DE LA IDENTIDAD VISUAL CORPORATIVA
}

\section{THE IMPORTANCE OF CORPORATE IDENTITY}

David Caldevilla Domínguez: Profesor del Área de Comunicación en la Universidad Complutense de Madrid, la Universidad Europea de Madrid y Escuela Superior de Estudios de Relaciones Públicas david.caldevilla@ccinf.ucm.es

\section{CURRÍCULUM VITAE}

Diplomado en Magisterio por la Universidad de Zaragoza (España), licenciado en Comunicación Audiovisual por la Universidad Complutense de Madrid (España). Profesor en la Facultad de Ciencias de la Información de la Universidad Complutense. Secretario General del Fórum Internacional de Comunicación y Relaciones Públicas (España) y autor de varios artículos en revistas universitarias. Director de Operaciones de Imagométrica, s.l. y ex directivo de varias firmas españolas del ámbito de la mercadotecnia.

\section{RESUMEN}

La identidad corporativa es la manifestación física de la marca. Hace referencia a los aspectos visuales de la identidad de una organización. Esta identidad corporativa está relacionada directamente con la historia o trayectoria de la empresa, los proyectos de la misma y su cultura corporativa. Incluye un logotipo que es la pieza fundamental para identificar porque condensa el significado de la entidad. Todo esto y los elementos de soporte se recogen en el Manual de Identidad Corporativa. Pero 
no se puede construir una identidad visual a partir de un logotipo. Hay que diferenciar entre corporativismo y corporatismo.

\title{
PALABRAS CLAVE
}

Identidad corporativa - Logotipo - Corporativismo - Sujeto - Signo

\begin{abstract}
Corporate identity is the physical manifestation of the brand. Refers to the visual aspects of the identity of an organization. This corporate identity is directly related to history or history of the company, draft it and its corporate culture. Includes a logo that is the cornerstone to identify because it condenses the meaning of the entity. All this and the support elements are reflected in the Corporate Identity Manual. But you can build a visual identity from logo. We must differentiate between corporatism and corporatism.
\end{abstract}

\section{KEY WORDS}

Corporate Identity - Logo - Corporatism - Subject - Sign

\section{ÍNDICE}

1. La identidad visual corporativa y la sociedad civil

2. El sujeto de la IVC

3. Sujetos y estrategias

4. Principios y efectos

5. Construcción del signo

6. Bibliografía 


\section{TEXTO}

\section{La Identidad Visual Corporativa y la Sociedad Civil}

La IVC es un saber incierto, demasiado actual y móvil. Al logotipo se le dedica una atención destacada porque es una pieza fundamental en la Imagen Visual Corporativa (IVC), tiene la función de identificación y es un factor privilegiado en cuanto al significado; es decir, en él se condensa la intención metafórica de la entidad.

La IVC comienza su desarrollo en los primeros años del siglo XX y llega a su época de máximo esplendor en los 80. La evolución en la concepción de la IVC podría resumirse como el paso, en un primer momento de logo a programa y posteriormente de programa a equipo IVC. La primera función que las empresas solicitan a las técnicas y saberes del IVC es el de proyectar una imagen positiva y, por encima de ésta, transmitir valores y diferenciarse, que sería el siguiente objetivo en las preocupaciones de la mayoría de las empresas.

Ya desde su genealogía, la identidad corporativa marcó un antes y un después en la comunicación persuasiva empresarial, pues apareció como la última rama especifica de la comunicación visual y del diseño, pero actualmente puede decirse que ha absorbido a todas las demás y que incluso programa y gestiona la mayoría de productos materiales y simbólicos de la empresa. Hoy, la identidad corporativa gestiona la comunicación y el paisaje visual, y es considerada en su globalidad la marca visual del poder.

La sociedad civil 
El término Identidad Corporativa posee connotaciones no explicitas que lo contaminan, tanto por la ocultación de sus referencias más pertinentes como por la potenciación de algunas de ellas en detrimento de las demás. No se puede construir una identidad visual a partir de un logotipo (o imagotipo), que es lo que comúnmente hacen los no profesionales, ya que la indagación sobre el hecho de la identidad podría llegar a anular el logotipo como material base. La ausencia de preguntas sobre la identidad global suele llevar a modelos visuales en los que la pieza central es el logotipo, es decir, una música sin letra o un espacio sin color.

\section{Corporativismo y corporatismo}

Muchos autores lo han estudiado detenidamente sin llegar a conclusiones axiomáticas. Así, lo corporativo hace referencia a grupos sociales activos en la sociedad, pero fueron los totalitarismos de diverso tipo los que adoptaron el término como autocalificatorio: corporativismo. Pasada la segunda guerra mundial se adoptó el nombre, entendido como una nueva forma de organización de la sociedad civil o un nuevo control sobre la misma. Es pues, el término sociedad civil, clave para dar a lo corporativo un contenido que no lo desarraigue de sus orígenes históricos.

Un poco de historia: Con la revolución francesa (1789-1799) apareció un nuevo concepto social (aunque éste existiera ya en el ámbito legal desde los griegos y romanos), el de lo privado, que da origen al estado moderno y a la sociedad civil. Lo privado es el espacio de la razón, la posesión y disfrute de la propiedad privada de bienes, una situación que da lugar a la ciudadanía. El pensamiento privado se convierte en la virtud pública y por otro lado, el contrato social es una de las formas de explicar el fenómeno paradójico por el que un hecho privado, pero reconocido como universal, se transforma en un hecho público llamado opinión pública, tantas veces coincidente con la opinión publicada. La opinión de los poseedoresconocedores (o guías de opinión), marca la opinión pública no solo en los asuntos 
relativos a los bienes sino también a su disfrute. La opinión pública es, por tanto, un elemento propio de la sociedad civil y tiene un carácter marcadamente liberal lo que genera desigualdades de clase. La sociedad civil tiende a la organización de intereses y a la creación de órganos de opinión que desembocarán en medios de comunicación para masas (que no de masas). De esta manera, los intereses se agrupan en corporaciones, que asumen un poder de negociación con otras corporaciones y con el Estado. Las presiones ejercidas sobre los Estados por parte del poder económico (el imparable surgimiento de la alta burguesía por oposición a la nobleza) han marcado el carácter de los Estados actuales.

La opinión pública, al ser asumida por los medios de comunicación masivos y alentada por los creadores de opinión, se transformó en publicidad. Se le llama opinión pública a la opinión privada de los ciudadanos una vez homogeneizada, sumada cuantitativamente como opinión publica generada por los creadores de opinión. La publicidad organiza el imaginario en el que se fragua el deseo del consumidor y como creadora de opinión de consumo, se ha constituido como un poder de negociación, una corporación en sentido pleno, mediadora de flujos económicos y culturales a nivel planetario. La competencia por la posesión de los medios de creación de opinión ha proporcionado a la publicidad un protagonismo que desborda su antiguo marco de detallista. El emisor ya no acude a los medios sino que los gestiona. La publicidad se ha constituido en empresa supranacional, con una hegemonía que tiene que ver con la instauración de una cultura de empresa, estándar que unifica las miniculturas de las empresas particulares y se establece como estándar cultural dominante, enfrentándose incluso a la cultura de Estado.

Otro es el caso de la denominación de identidad global ya que hace referencia a las características técnicas de un tipo de comunicación visual, y no a una situación de usurpación de una técnica por su principal cliente. El predominio de la cultura occidental es un hecho de carácter hegemónico que merece una crítica desde el punto 
de vista de la pluriculturalidad. No obstante nos hallamos siempre en un calljón sin salida dada la tendencia genética del ser humano al etnocentrismo.

Historia y definición del concepto

La identidad visual existe desde siempre. La sociedad siempre ha estado estructurada y diferenciada, y han sido los signos externos los que lo han expresado. Sin embargo, el campo de nuestro estudio ha de restringirse a la identidad visual intencional, conativa (a veces fática) y estereotipada. A comienzos de siglo empezó a extenderse un movimiento que tiende a configurarse como disciplina, como saber especializado y como uno de los aspectos de la comunicación gráfica. Su desarrollo corre paralelo al desarrollo del moderno concepto de diseño incluido el basado en la nuevas teconologías milagrosas.

Suele considerarse al socialista utópico británico William Morris (1834-1896) como el iniciador de este movimiento de unificación del arte, de la artesanía y de la industria. En su aspecto formal la IVC surge como una de las armas de diseño gráfico, conviene diferenciar la comunicación gráfica del diseño gráfico (aunque no como antagonistas), que apareció como un hecho nuevo y moderno. El diseño nació en 1919 y la IVC fue creada por el diseñador y arquitecto alemán Peter Behrens (18601940), al planificar una verdadera identidad global para la empresa AEG (Allgemeine Elektrizitaets-Gesellschaft, en español Asociación General de Electricidad, s.a.). En los años sesenta, la arquitectura de las imágenes de empresa integra también la modernidad gráfica. La apelación constante a los signos de identidad y diferenciación particulares parece expresar un contrapunto a esa falta de identidad generalizada. El diseño gráfico comprende la utilización conjunta de todos los distintos sectores especializados de la técnica comunicativa gráfica. El campo especifico de la tipografia comprende tanto la confección de logotipos como de las tipografías realizadas ex professo para identificar una línea de comunicación 
corporativa. El de la señalética todo el desarrollo de la señalización ambiental, interior y de personas y objetos, aparte de los contenidos específicamente señalatorios que los elementos de identidad comprenden en sí mismos. El campo editorial atenderá a todas las comunicaciones escritas. Y el sector publicitario controlará todos los aspectos de comunicaciones masivas, en pleno terreno ya de las relaciones públicas.

La IVC es pues una imagen de tipo complejo, una mezcla controlada de todos los recursos de manifestación visual, esto supone un dominio de todos esos recursos. La IVC se enclava dentro de los "sistemas erráticos" ya que es una imagen progresiva, que no se puede aprehender ni recibir desde la observación de una propuesta o hecho comunicativo unitario, sino tras la acumulación de sucesivos impactos que la van configurando. La imagen es, pues, de tipo global, solo perceptible en su conjunto. Una IVC nunca esta completa, siempre se encuentra en formación y en interacción con el espectador. La imagen es el lenguaje simbólico de presencia indicial a través de geografías y cultos particulares. Quizá aquí se manifieste el concepto gestaltico en toda su magnitud ya que el todo es más que la suma de las partes conformantes.

No existe una única representación de este mundo fragmentado y complejo. Sin embargo se dan ciertos rasgos de lectura común que constituyen indicadores de un mapa que orienta una cierta manera de ver el mundo. La IVC es un sistema de lectura global que, apoyado ya de inmediato en una red comunicativa mundial, constituye una aportación visual muy característica de nuestro tiempo. Una nueva aldea cuyo alfabeto visual común son los signos de identidades cuyo carácter global es el más sobresaliente: el de las entidades de tipo económico. La parcialidad de este mapa hace que probablemente distorsione la percepción de la realidad, pero hoy por hoy parece admisible que nuestra interpretación del mundo tiene un carácter 
económico, y que dicho tipo de economía está marcado a su vez por las grandes corporaciones.

\section{El sujeto de la Identidad Visual Corporativa}

Sujeto perceptivo

La imagen global es una imagen difícil de percibir, puede compararse con otros tipos de percepción, como el estilo. Exige un distanciamiento y una memoria recopiladora de los diversos elementos, una preparación mental especializada, tanto en el constructor de la imagen como en el cliente. Se requiere una anticipación imaginativa. La expresión visual, ritualizada por medio de la elaboración de logotipos, y rutinizada por manuales, es la parte fácil. La configuración mental de la imagen global no sólo comprende aspectos relativos al sujeto de la imagen, sino también a dos tipos de estrategias: de identidad y de visualización. La percepción de la imagen global (en un eclecticismo cultural y un concepto holístico de ámbito de desarrollo humano) tiende a organizarse como identidad, mediante el establecimiento de rasgos permanentes. Esto nos lleva a anticipar la noción de programa como sistema en el que se desarrolla un propósito controlado y orientado a conseguir una cierta forma global.

La imagen global en objetos unitarios

En todo programa es necesaria la existencia de unos elementos básicos simbólicos, de una gramática que especifique las reglas por las que esos elementos se combinan, y una finalidad o propósito definido.

EL LENGUAJE: es un tipo de imagen global y sus elementos simbólicos mínimos son los fonemas o las letras. La gramática es el conjunto de reglas. El programa es la 
comunicación mediante frases inteligibles que desembocan en un sentido pragmático.

LA TIPOGRAFIA: Constituye un programa especializado, en una tipografía pueden identificarse elementos básicos como uñas, remates, gotas, que proporcionan los elementos diferenciadores.

LA IDENTIDAD EDITORIAL: se refiere a la identidad de los productos, caracterizados por programas que expresan el concepto de globalidad.

PICTOGRAMAS: son modelos con lenguaje icónico, a medio camino entre la letra y la imagen. Es un concepto derivado de las escrituras orientales.

Consideremos la imagen global referida a sujetos complejos, habitualmente llamados corporativos. La denominación de corporativos atiende a una calificación de espacio de imagen. La imagen global es una clase de imagen que elabora la tipología desde sí misma y no por el objeto coyuntural sobre el que se aplica.

La imagen global en objetos complejos

Como objetos diferenciados de imagen global encontramos hechos o acontecimientos, desarrollados según el eje espacio-tiempo que puede o no coincidir entre el emisor y el receptor; entidades y productos cuya versión unitaria ya ha sido vista como ejemplificación de los programas y de la imagen global y que son susceptibles de un tratamiento complejo cuando constituyen el centro de la operación de una entidad.

Debemos recurrir a un nuevo concepto, el iconómetro. "Se trata de un instrumento que mediante la aplicación de una escala constituida por los atributos determinantes 
del carácter nacional nos permite trazar una gráfica, el iconomgrama, que representa el perfil icónico de la organización que hayamos investigado" en palabras del profesor Solano (La Imagen Corporativa como efecto de la asunción de la Responsabilidad Social, ver bibliografía).

Los acontecimientos pueden clasificarse en:

1 - Acontecimientos espaciales: el determinante espacial constituye un elemento fundamental que obliga a pensar, a prefigurar toda la imagen desde su perspectiva. Todo es con espacio y nada es existente sin él. Su factor dominante en la construcción mental es el espacio. La imagen mental previa a cualquier visualización contará con el espacio como principio generador de la imagen global, entendida como imagen progresivamente armada. Es la base del pensamiento de Kant junto con el siguiente apartado.

2 - Acontecimientos temporales: su identidad consiste en modular un tiempo delimitad por un principio y un fin (definición aristotélica). Los sucesos delimitados en el tiempo se caracterizan por un comienzo y un fin. La programación puede ser plena y uniforme o puede ser progresiva, ampliando aspectos de la imagen hasta su final. Para estos acontecimientos se crean identidades cuyo sujeto no es precisamente el comité organizador, sino el evento mismo, quien a través de la imagen pretende hacerse presente y movilizar los ánimos durante un tiempo delimitado. Son casos de identidad que deben ser tratados de una forma especial, su dominante visual suele ser ejercida en el sector de la comunicación y la promoción publicitaria de actos y patrocinios.

3 - Acontecimientos espacio-temporales: Tiene las características simbólicas de la primera y el carácter ambiental de la segunda. Ej. à las Olimpiadas. Es una relectura holística. 
Todo cambia cuando nos referimos a sujetos a quienes se puede atribuir responsabilidad, con capacidad de actuación. Las entidades se pueden dividir en públicas, privadas y mixtas.

Entidades públicas: de representación ciudadana como el Estado, las Autonomías, los Ayuntamientos, etc. Su ámbito de actuación es el espacio sociopolítico normalmente.

Entidades privadas: son mayoritarias y de mayor inestabilidad. Se diferencian dos clases: las institucionales; corporaciones parainstitucionales como asociaciones, fundaciones, partidos, etc. Y por otro lado las comerciales; son las mas conocidas, su identidad corporativa se enclava en el espacio más amplio de la imagen global.

Entidades mixtas: son entidades privadas con carácter público como los servicios de transporte, comunicaciones, combustibles...

Entidades locales: lo local va siendo desplazado progresivamente del campo de la IVC y relegándose a la comunicación de tipo artesanal.

Entidades supralocales: las corporaciones de tipo económico han seguido dos tendencias: por un lado la institucionalización bajo la guía de los estados, y por otro las autonomías comerciales y financieras han operado diferentes tipos de concentración y fusiones llegando a nuevas formas de monopolio u oligopolio. En este caso, las características de una IVC adecuada tenderán a imponer ciertas formas concretas de lectura, en una especie de imperialismo cultural exportable y descodificable allende las fronteras en que fuera concebido. 
El campo de los objetos es disperso, abundante y conocido. No se suele hablar de identidad corporativa de productos, al no tratarse de una corporación, aunque sí se puede hablar de imagen global.

\section{Sujetos y estrategias}

La imagen global comienza a ser proyectada mentalmente. A veces deriva de una situación y otras veces es un acto deliberado de orientación de empresa, con el fin de llevar a cabo una acción definida. Después de la selección de estrategias visuales se desarrolla el proceso de selección de elementos visuales apropiados.

\section{Estrategias de identidad}

Se trata de elecciones previas a la visualización, se encuentra en la fase de la configuración de la imagen global. Aquí no trataremos el concepto de táctica por demasiado particular para nuestra reflexión.

Identidad unitaria: denominada también monolítica. Derivada de los atributos del sujeto o bien de una decisión sobre el tipo de identidad que una entidad se quiere atribuir. Es adecuada a los tipos de representación permanentes y unívocos, oportunos para las entidades públicas, de un solo servicio, un monopolio, un producto concreto. Ejemplos: bancos, líneas aéreas, etc. Tal estrategia puede ser un acto voluntarista o bien resultado de una situación, de la adquisición paulatina de una identidad sobre la que se ejercita la decisión de mantenerla como identidad.

Identidad diversificada: supone la ruptura con el monolitismo. Pueden distinguirse dos variedades: endorsed y branded, que podría traducirse en "compartidas" y "distribuidas". Dentro de la estrategia compartida diferenciamos dos tipos: o bien una entidad asimila a otras, por fusión, absorción o adquisición, o bien se desgaja en 
nuevas divisiones dependientes de la primera. Las maneras en que este hecho se visualiza van desde el mantenimiento de aire visual de familia hasta la expresión de dependencia.

Identidad de marca: es la que se corresponde con los productos como sujetos de identidad visual. El logotipo sirve para los acontecimientos y entidades, a diferencia de la marca, para objetos y productos. La estrategia de identidad de una entidad esta basada en la marca de un producto. Ejemplo: Nutrexpa y su Cola-Cao o Inditex y Zara.

Estrategias de visualización

Imagen cerrada: imagen programada con el mínimo de variación, tanto en sus elementos como en su declinación o en sus aplicaciones, también restringidas. Ejemplos: escudos.

Corresponden a sujetos de carácter permanente y estable, con estrategias y planteamientos de tipo unitario o monolítico. Las entidades comerciales de tipo unitario y las marcas de productos pueden también adoptar este tipo de visualización. Ejemplos: escudo del Estado, de universidades, símbolos de Mercedes, Citroën, Renault, Coca-Cola o IBM.

Imagen abierta: puede efectuarse por varios procedimientos: primero, declinación, variaciones de color, forma, tipografía... En segundo lugar, distribución, consiste en la explotación de varios sistemas de unidades portantes de la identidad (símbolo, mascota...). El tratamiento de los elementos morfológicos no se efectúa como en la declinación, en forma de variantes, sino que se integran en lo que más adelante se denominarán las unidades básicas del programa visual. Y por último, interpretación, variaciones permisivas en mayor o menor grado de la imagen principal, que pueden 
dar lugar a derivaciones que llegan hasta lo decorativo y lo arbitrario. La imagen abierta conviene a todo tipo de sujetos e identidades, pero parece alejarse de las conveniencias de los sujetos públicos y de las estrategias monolíticas (Juegos Olímpicos, Telefónica, Pans\&Company, las cadenas de TV...)

Imagen poliforme: estrategia visual que se sitúa en el extremo opuesto de la imagen cerrada. Tiende a una supuesta disolución de la identidad, a una identidad difusa o borrosa. Esta tipología es difícil de aceptar. Esta imagen se declina y modula según las circunstancias, al tiempo que permanece reconocible. Puede exigir un aprendizaje visual y el conocimiento de un código de reconocimiento. Supone una propuesta de juego visual que se desborda por el camino de la variación y de la imaginación, con riesgo de caer en la disolución de la imagen. Ejemplo: MTV.

\section{Principios y efectos}

Una imagen compleja necesita principios que ordenen y combinen todos los elementos conforme a un fin. Una imagen global se enfrenta a problemas perceptivos que deben ser programados. Algunas investigaciones parecen apoyar la idea de que a los receptores les gustan más los logos complejos que los sencillos, son preferibles los logos con imagen (imagotipos) a los simples tipográficos.

Principio de representación / formalización

La representación es una función propia de los signos ya que todos ellos poseen algo de las tres formas de representar. Pueden tener varios referentes $\mathrm{u}$ objetos a los que sustituyen. Puede complicarse si tenemos en cuenta que en el terreno de lo visual se da un doble estatuto de la imagen, es decir, lo que vemos puede ser una forma concreta y a la vez la representación de otra. POr ejmplo un toro es un toro y el referente icónico de Bodegas Osborne; una paloma es una paloma y la paz. El 
referente principal es la entidad o hecho en cuestión para el que se quiere confeccionar una imagen visual. Por consiguiente, la imagen buscada, planificada y visualizada siempre será una convención, en muchos casos, el referente puede ser un producto u objeto, en tal caso, el signo tenderá a parecérsele para representarlo. Hay que entender el principio simbólico o de representación como un proceso de significación, de sustitución. En conclusión, el principio de representación tiende a que la imagen en su globalidad represente a la entidad de que se trate. La representación, dentro del campo de la imagen corporativa, tiene sus límites y formas de ser interpretada provenientes de diversos hábitos o ideologías referentes a la imagen y a sus valores. La significación de una imagen es aquello que representa para nosotros. Una esvástica para un budista es un signo de buena suerte y vida feliz, para un europeo es una parte aciaga de la historia y para un judío un símbolo de muerte. La imagen tipificada como de identidad corporativa atiende a circunstancias tales como su percepción rápida, fácil retención..., aunque se insiste en las marcas y logotipos como imágenes típicas de la imagen global, existe la posibilidad de construir una imagen global por otros procedimientos.

Principio de integración / universalidad

Principio metodológico y genérico, el más característico de la imagen global. Alude al carácter metalingüístico de todo programa, en el sentido de que expresa una serie de acontecimientos comunicativos de los que se predica un mismo código que los califica y hace coherentes. En el plano visual, tenderá a la coherencia formal y de uso de todos los elementos visuales y tenderá a asimilar la no discordancia del programa visual con otros elementos de imagen, lo que también será objeto de normativización a través de gestión y coordinación de imagen. Existen varios tipos:

En primer lugar, universalidad cultural; la imagen global pretende dirigirse a todo tipo de observador genérico, implica la posibilidad de diversos hábitos y culturas. 
En segundo lugar, universalidad temporal; presupone una lógica de la perduración, se trata de la universalidad entendida como permanencia, en el momento inicial una identidad se identifica a sí misma. La continuidad en la identificación es una cuestión asimilable a un capital de imagen.

Otro tipo es la universalidad de destinatarios; hay que contemplar el conjunto de los destinatarios. Existen tres clases de destinatarios:

De clase superior a la entidad, proscriptores de la entidad, a ellos se remite con su imagen para hacerse acreedora de su favor.

De clase intermedia, constituida por grupos de referencia a los que se pretende igualar o superar.

De clase de usuarios a quienes va dirigida la actividad o los productos de la entidad.

Principio de estandarización / diferenciación

La normalización es uno de los efectos de la producción industrial, la imagen global se aplica a sí misma una normalización. La estandarización puede ser contemplada en sus repercusiones en una economía de escala, abarata costes con la reproducción de unos pocos modelos normalizados y repetidos. La necesidad de normalización también deriva de que la producción de una imagen visual global exige una constancia formal que limite los grados de libertad perceptiva de la imagen. El objetivo final de la imagen global es la identificación clara de la entidad y de sus atributos, a veces las entidades tienen una idea de su propia identidad consistente en asemejarse a otras líderes. Todas las entidades quieren poseer los mismos atributos de modernidad, liderazgo, positividad, futuro, etc. El espacio de la visualidad 
dispone de un repertorio tan amplio que puede garantizar bastantes grados de diferenciación.

La imagen global tiende normalmente a deslizarse hacia la publicidad, adoptando sus hábitos y su permanente cambio. La repetición y la visibilidad indicial se han convertido en las únicas medidas del éxito. La IG es un índice y sus elementos visuales apuntan a la realidad concreta. Falta aún una unidad de medida para consagrar este concepto a los altares de ciencia.

Volver a principios y efectos Volver al principio del artículo Volver al principio

\section{Construcción del signo}

Como ya hemos dicho, el logotipo es el signo privilegiado de la IV, suele ser central, sintetizador y punto de partida de un proceso de desarrollo. La importancia que se le otorga es también un hecho susceptible de análisis.

En la construcción formal se recurre a los principios de la psicología de la recepción a través de leyes de la configuración de la forma: pregnancia, semejanza, proximidad, simetría, cierre, exhaustividad y jerarquía. Todos ellos se pueden resumir en el de pregnancia, por el cual algo se manifiesta como percibido. El conjunto de tales principios trabajan con el único propósito de definir una forma sobre un fondo.

Geometrización: se da por lo general una constante hacia el dominio de la forma a través de métodos de racionalización. La geometría impone una rejilla de racionalidad, actúa como una domesticación. Los programas de Identidad Visual adoptan por lo general esta visión geométrica, a través de cuatro procedimientos:

Sistemas compositivos: el principio de proximidad aglutina los elementos visuales en una composición central. 
Regulación del trazado de la imagen: a partir de paralelas, centros, simetrías, etc.

Acotaciones de proporción.

Estilización: adecuación de la forma ideada mentalmente a figuras compuestas por elementos morfológicos elementales, conducidos hacia las figuras menos complejas.

Nitidez: la imagen construida debe soportar condiciones de visibilidad y lectura adversas sin perder su definición.

Legibilidad: el signo logotípico se desarrolla a través de una serie de tamaños muy diversos, tiene también unos límites que los manuales intentan controlar, y que son de tres tipos principales:

La dependencia de la agudeza visual (el ojo impone un límite a los tamaños reducidos),

Las limitaciones técnicas y la autorepresentación (la entidad propietaria de un signo al que atribuye su representación puede admitir un menor o mayor tamaño como digno o desmerecedor de su auto-aprecio).

La legibilidad puede verse afectada no solo por el tamaño sino por la contigüidad: un signo situado en un contexto puede verse afectado por el ruido visual. Se suele dotar a los signos de la IV (Imagen Visual) de espacios de silencio, que eviten la aproximación de otros signos que puedan interferir en su lectura.

La conjunción de geometrización, nitidez y legibilidad pueden ser factores importantes en la realización del principio de estandarización: permiten la adecuación fácil a diversos soportes y materiales. 
Todas las características constructivas de los signos son derivadas de la observación empírica. Actualmente el entorno impone una visión acelerada, tanto por la movilidad urbana como por los medios de locomoción, y por la competencia visual que obliga a una más rápida captación de los estímulos, una mayor simplicidad.

Estamos ya en plena era postindustrial, de producción en serie, de capitalismo de consumo, de celeridad en la comunicación de signos, de globalización. La limpieza de los signos ha sido progresiva, como puede apreciarse en las secuencias históricas de los logotipos de diversas entidades, cuyos rediseños han ido coincidiendo con la adecuación a una mayor pregnancia, simplicidad, claridad e inmediatez de lectura.

\section{Semántica y retórica del signo}

El significado de las letras, aunque expresen sonidos o palabras, depende de la forma de estar enunciadas, dichas, escritas o de su enunciación visual. La tipografía en sí es clasificable como signos abstractos, la estructura básica de las letras no existe como materia visual. La clasificación de Vox adoptada por la asociación internacional ATYPI, consiste en una simple división en clásicas, modernas y manuales y realiza un equilibrio entre la clasificación técnica y la semántica, basada ésta en el significado histórico y genético de las formas tipográficas. Pero existen otras clasificaciones como el método diferencial semántico de Osgood, cuyos tres ejes principales son la evaluación, la potencia y la actividad, a propuesta de Cerezo, con tres ejes también, historicidad, vitalidad y claridad. Por otro lado la de Blanchard con dos ejes: pulsión/normalización y nuevo/antiguo.

Clasificación tipográfica: existen tres elementos generadores de significación tipográfica:

Los caracteres formales, 
Su origen histórico y

Su origen psicológico o intencionalidad.

Una de las clasificaciones más genéricas es la que divide los caracteres tipográficos por su aspecto formal en tipos romanos, de palo y manuales. Las de palo son las más antiguas por obedecer a escrituras primitivas, las romanas proceden de la lapidaria romana, caracterizada por remates en la terminación de los trazos principales. Cuando las exigencias de la publicidad optaron por los grandes tamaños de letra ésta hubo de ser de madera, sólida y robusta, sin remates que pudieran romperse. Aparecieron los tipos lineales a los que se llamó grotescos, comparados con la gracia y elegancia de la letra romana, la modulación y trazo de la romana se oponen a la rigidez y elementalidad de la de palo. Los tipos manuales han pasado a mecanizarse como tipos de imprenta, pero manteniendo su carácter. Posteriormente aparecen los tipos mixtos, mezclas de algunos de los anteriores. Esta progresiva iconización ha alcanzado hoy, inspirada por la facilidad tecnológica y reducida educación visual, a verdaderas psicopatológicas de la letra. La explosión tipográfica actual ha conectado con un individualismo de expresión narcisista, derivado de un uso de las nuevas tecnologías muy guiado y condicionado por un tipo de consumo.

Cierto tipo de entidades no admitirían que sus atributos se situasen en zonas negativas ni irracionales, la multiplicidad de tipos de entidades, el fomento del autoempleo y ciertas topologías empresariales situadas en la "nueva economía", han fomentado rupturas de comportamientos tradicionales y de estándares visuales.

Existe una semántica del logotipo alcanzable mediante el conocimiento del sistema tipográfico en sus múltiples variaciones. Hay también una semántica del símbolo que permite desglosar diversos significados. La unidad básica en que se expresa la identidad visual puede ser solo el logotipo o el logosímbolo como conjunto de 
logotipo y símbolo. En el caso del logotipo, la significación proviene del sistema lingüístico, sin embargo, al entrar con el símbolo en interacción, se establecen también relaciones de tipo plástico. Las relaciones pueden ser de redundancia, de complementación o dialéctica.

Las relaciones plásticas entre logotipo y símbolo se manifiestan mediante la composición (colocación de los elementos según reglas que producen legibilidad y percepción estética). El logosímbolo puede configurarse bajo un esquema de yuxtaposición, o bien aparecer en un esquema de implicación.

El color es muy susceptible de interpretaciones personales. La teoría del color aplicada a las imágenes de IVC puede considerar dos campos fundamentales: la aplicación del color como elemento de entorno, funcional o ambiental y su aplicación a la unidad básica. En el primer caso, puede tratarse puede tratarse de una seña explicita de identidad, es decir, el color como elemento fundamental de identificación o como elemento de recuerdo.

El contexto exterior

El carácter global de La IVC y su percepción y evolución desarrolladas en el tiempo hacen dificultoso su seguimiento, hay ciertos entornos en los que la imagen se desenvuelve, con los que interactúa y que generan experiencias que pueden retroalimentar la construcción de esa misma imagen

Los símbolos de identificación son susceptibles de apropiación legal, uno puede ser propietario legal de su propia imagen ya que puede registrarla en la Oficina Española de Patentes y Marcas, que recibe más de 80.000 solicitudes al año. Aunque las posibilidades combinatorias de la imagen plástica son infinitas, no se está a cubierto de coincidencias o semejanzas casuales. El registro de marcas puede 
suministrar una interesante información al respecto, y además se ocupa de limitar la competencia entre los diversos identificadores. También hay posibilidad de crear una distancia perceptiva mayor o menor entre la imagen de una entidad y las imágenes de otras entidades. Esto puede dar lugar a pleitos cuando se piensa que no se respetan esos espacios subjetivos.

El espacio exterior es cada vez más el contexto de las imágenes globales. La IVC es uno de los elementos que irrumpe en el paisaje urbano. La "tiposfera", esa zona de unos pocos metros sobre el suelo donde se encuentran todas las llamadas y reclamos tipográficos, ha llegado a crear un nuevo paisaje artificial que en unos casos caracteriza ciudades y en otras crea un caos visual. En este conjunto las señales de la IVC entran en competencia por tres caminos: la competencia entre sí (ruido blanco donde ninguna comunicación es posible), la competencia arquitectónica y la competencia con los entornos históricos.

La identidad visual no es ya una referencia o una orientación, sino un interlocutor que intenta, a través del eslogan, añadir un sentido no incluido en el símbolo y normalmente coincidente con el carácter dominante de las relaciones económicas y de mercado de la sociedad actual.

Programas y manuales

$\mathrm{Al}$ abordar los manuales como expresión del programa de visualización, se seguirá un orden lógico semejante yendo de lo general a lo particular. Es ahora cuando tratamos de llevar al plano plástico de la representación los elementos concebidos, que intentarán reflejar el tipo de imagen.

Toda normativa debe tener en cuenta un plazo previsible de aplicación indefinido o calculado, es conveniente la constitución formal de un equipo de control interno y de 
consultaría externa. Las entidades cerradas suelen utilizar manuales cerrados y sin embargo, las entidades con evolución usan manuales que permiten sustituir o añadir normas conforme vaya siendo necesario.

A través de los manuales se puede observar que hay un tipo predominante de texto. Un mayor número de identidades visuales tienden a las tipologías cerradas, y en menor grado a las abiertas. La perspectiva sincrónica se refiere a la estructura normalizada, un mapa extendido en el que podemos observar las partes y su sintaxis en un solo golpe de vista.

Previa a la determinación de la estructura normativa, el establecimiento de una metodología de trabajo y el desglose de elementos que resulten operativos para la formalización, visualización, de la entidad. Los técnicos o equipos expertos en comunicación corporativa estarán integrados en el equipo de trabajo de la entidad desde el comienzo. La búsqueda de la exteriorización de los significados apropiados y pertinentes para una entidad se realiza en dos pasos: en la determinación de los atributos y en la visualización de los mismos.

Antes de comenzar la programación del desarrollo visual han de quedar explicitados unos temas concretos: delimitación de los fines de la operación de imagen, determinación de las conexiones históricas y de los valores culturales a mantener, definición de atributos pertinentes y jerarquía de los mismos, configuración de los receptores principales en los diferentes niveles, posibilidad de desarrollo en cuanto a soportes, procesos y tiempos, y por ultimo, definición de la denominación de la entidad.

Hay que destacar las dificultades que pueden encontrar ciertos nombres en su recurso y pronunciación, datos que sin duda complicarán la visualización. 
Un manual normativo suele constar de tres partes: unidades básicas, desarrollo y elementos técnicos. Las unidades básicas son piezas primitivas y constantes que se aplican a todas las circunstancias previsibles y se suelen dividir en tres: un conglomerado simbólico compuesto por los colores y la tipografía.

El logotipo suele ser el primer elemento que abre el manual, su traducción sería palabra-tipo y se entiende como la manera de expresar visualmente la denominación de la entidad, su forma visual.

El símbolo es la parte no lingüística del identificador de la entidad. Suele consistir en una figura más o menos abstracta portadora de información no transmitida por la denominación y su formalización logotípica.

El logosímbolo es la integración de logotipo y símbolo. La hegemonía del logosímbolo ha hecho que este sea considerado no solo la pieza favorita de la identidad corporativa sino que se le suele identificar con ella, puede calificarse como un grave error abordar la construcción de una identidad visual partiendo del logotipo.

La importancia dada al logotipo se refleja también en el volumen que sus especificaciones ocupan en los manuales normativos de la imagen visual.

El color entra en competencia con otros usos no identificativos y correspondientes a otros espacios visuales como la publicidad. Su poder identificador puede verse limitado por requerimientos materiales, es decir, el color llega a ser identificativo s partir de cierta extensión relativa al espacio de uso. El color o colores principales suelen ser los que figuran de manera dominante en el logotipo aunque suelen tener más importancia técnica los colores que llamamos secundarios o complementarios porque: prevén el entorno adecuado para que el logotipo y sus colores principales 
adquieran toda su relevancia, se aplican también como colores de entorno habitacional y pueden tener un sentido funcional.

En la tipografía se suele especificar una principal y otra secundaria, la primera se refiere normalmente a la utilizada en el logotipo. La tipografía puede ser estándar (de lectura) o bien creada como identificadota de una identidad. La tipografía secundaria se emplea como complemento de la primera, la elección de tipografías supone unos conocimientos especializados ya que no todas las combinaciones tipográficas son adecuadas, elegantes o funcionales. En muchos casos la tipografía es un elemento uniformador mas que identificador.

Se trata de establecer unas reglas según las cuales los elementos primarios pueden combinarse con los objetos y espacios. Hay tres sectores de aplicación bien delimitados: el comunicativo, el señalético y el promocional. Las prescripciones del manual no son un arma defensiva frente a la variabilidad de la vida y las situaciones, sino una guía.

La imagen visual entra dentro del diseño, que no es más que una actitud comunicativa o creadora cuya forma de producción es de carácter industrial por lo que se deben proveer modelos y prototipos reproducibles mecánica, indefinida e idénticamente. Puesto que la mayor parte de la identidad visual se ejerce convencionalmente en el sector gráfico, la mayoría de los soportes se preparan con este fin.

Tipologías de manuales:

Manuales exhaustivos: agotan las posibilidades y precisan todos los detalles correspondientes a todas las situaciones previstas, se encuentran en sintonía con las estrategias de tipo cerrad. 
Manuales elementales: reducen su normativa a lo esencial, dirigidas a entidades de estructura más descentralizada.

Manuales modulares: indican la previsión de distintas necesidades o velocidades de cambio de diversos sectores de la entidad, dirigidos a entidades abiertas o no totalmente conformada.

Doble versión: un manual completo y de poca difusión que permanece normalmente en los centros principales de decisión.

Volver a construcción del signo Volver al principio del artículo Volver al principio

\section{Bibliografía}

CALDEVILLA DOMÍNGUEZ, David: Las Relaciones Públicas y su fundamentación. Editorial Visionnet. Madrid. 2004.

CALDEVILLA DOMÍNGUEZ, David: Relaciones Públicas y cultura. Editorial Visionnet. Madrid. 2005.

GONZÁLEZ SOLAS, Javier: Identidad Visual Corporativa. Editorial Síntesis. Madrid. 2002.

SOLANO SANTOS, Luis Felipe: La Imagen Corporativa como efecto de la asunción de la Responsabilidad Social. Editorial Publicarya. Madrid. 2008.

VILLAFAÑE, Justo: Imagen Positiva: Gestión estratégica de la imagen de las empresas. Editorial Pirámide. Madrid. 2002. 